\title{
HOW SOCIAL ARE FLOOD RISK MANAGEMENT PLANS IN SPAIN?
}

\author{
GUADALUPE ORTIZ ${ }^{1}$, PABLO AZNAR-CRESPO ${ }^{1} \&$ ÁNGELA OLCINA-SALA ${ }^{2}$ \\ ${ }^{1}$ Department of Sociology I, University of Alicante, Spain \\ ${ }^{2}$ Sciences Po, Paris School of International Affairs, France
}

\begin{abstract}
Due to the weaknesses of the technocratic model in providing integrated, sustainable flood risk management, a new approach has emerged aimed at promoting adaptive strategies by means of nonstructural measures, such as raising awareness among exposed populations and improving their adaptive response to risk. However, the emerging nature of these measures makes it necessary to analyse the way in which this social approach is being implemented in the day-to-day practice of flood risk management. Thus the aim of this paper is to assess the integration of social actions of risk response and public participation into risk management processes. To this end, 14 Spanish flood risk management plans (FRMPs) were reviewed and codified by means of a documentary content analysis. The coding process was designed according to the models of social capacity building and participatory assessment in flood risk management. The resulting analysis provided information on the characteristics of participatory processes in the development of FRMPs and on five areas of social initiatives for capacity building: knowledge, financing, motivation, governance and networks. The results revealed the limited quality of participatory processes due to procedural weaknesses and low representation of social actors. Also, social actions were focused on the promotion of risk awareness and showed a lack of technical detail that reduced their potential for implementation. Thus this paper argues that the social approach has not been transferred to practice in flood risk management, since the development of measures is still predominantly shaped by the traditional technocratic approach.
\end{abstract}

Keywords: disaster, natural hazard, social capacities, risk governance, non-structural measures, stakeholder, science-policy gap, social vulnerability.

\section{INTRODUCTION}

The technocratic paradigm prevailing in flood risk management has been called into question for its apparent limitations to provide sustainable and effective management [1], [2]. This paradigm is based on protection from and reaction to flooding through building defences aimed at draining floodwaters rapidly and effectively [3]. In line with this principle, flood risk analysis specialises in hazard studies that calculate the probabilities of periods of recurrence, model river courses in flood episodes and estimate direct material damages [4], [5]. In the area of management, the technocratic paradigm has led to the predominance of structural measures for retention, protection and drainage [6], [7], spurred by technological optimism and the belief in mastering nature [8]. These measures, since they are exclusively aimed at controlling the threat, have left aside factors such as land-use planning and its influence in increasing exposure to flood risk, the flow dynamics of historically floodable areas, and social vulnerability of the population [9]. This lack of attention to the whole set of forces driving risk creation has given rise to a reactive, deficient flood management model [10], [11] that has often been overwhelmed by the unforeseen size of events or by the population's high levels of exposure and vulnerability.

The inability of the technocratic model to create resilience to flood risk has favoured the appearance of new criteria and principles focusing more on adaptive management [12], [13]. This new approach calls for a transition from protection and reaction based on threat control, to prediction and adaptation based on strengthening the adaptive capacity of the risk exposure units [14]. The inclusion of adaptive criteria in management models makes it necessary to 
develop non-structural measures. These measures, rather than building physical defence facilities, are aimed at areas such as territorial planning and land use, the promotion of social awareness of risk and self-protection behaviours, the risk communication in the case of emergencies, institutional governance and legal reactions to disaster impacts [15]. The objective of such measures is not to mitigate or control the flood event but to reduce the exposure and vulnerability of the socio-territorial fabric as a whole [16]. Thus this new adaptive approach does not only involve analytical and technical changes in approaches to managing risk, but also represents a paradigm shift in the values mediating between the social, environmental and economic concepts of flood risk [17], [18].

One of the main paradigmatic consequences of this new management approach is its greater recognition of the social dimension of risk [6]. The idea that exposure units are proactive and can make adaptive responses in preparing for, confronting and recovering from risk obliges us to pay attention to the social processes behind such responses, particularly by analysing and managing social vulnerability [19]. This concept, the most frequently analysed variable in studies of the social dimension of flood risk [20], is defined as the sum of social, economic, political, institutional and cultural conditions determining the ability of people, groups and overall systems to tackle the negative impacts of stressful events and recover from the ensuing changes in the short, medium and long term [21]. The concept of vulnerability, then, goes beyond individual conditions of risk response, since it includes the forces creating it and enables the conceptualisation of the adaptive responses of systems as a whole. Owing to its integrated nature, social vulnerability can be seen not only as an operative concept or variable, but also as an overarching approach through which to understand the influence of the social structure in the creation of risk [22]. Due to its importance, studies of social vulnerability to flood risk have seen significant growth in recent years [23]. This research has mainly been aimed at assessing the socio-demographic conditions of exposure units [24], investigating the population's knowledge and perceptions of risk [25] and analysing models of socio-institutional governance of risk [26]. In the latter field of study, the emergence of social participation as a formula for proactive risk management is notable. Various analysts have indicated the need to enhance governance systems by expanding the community of social actors taking part in decision-making for the development and application of flood risk management measures [27]-[29]. Social participation in this field represents a means not only of democratising the development of management plans [30], but also of empowering the population by equipping it with the knowledge necessary for the effective application of responses to flooding [31].

Despite this recent growth in studies of the social dimension of flood risk, particularly through developing the social vulnerability approach, not enough evidence has yet been accumulated on how these new principles are being incorporated into the practice of risk management [32]. Some analysts have drawn attention to a science-policy gap in the field of flood risk management. Spray et al. [33] argue that risk managers and researchers have historically carried out their professional and scientific tasks in isolation from each other. According to these authors, risk managers have centred on factors for controlling the threat but have neglected to develop policies for land-use planning or reducing the population's social vulnerability. For this reason, management plans tend to lag behind contemporary knowledge and innovations in risk and disaster science [34]. Van Buuren et al. [13] argue that the technocratic tradition of risk managers, and political actors' need to satisfy public expectations of total protection through hydraulic defence works, are the two main factors behind the isolation of flood risk management and its difficulties in introducing innovative approaches that are sensitive to the social dimension. 
Once this research problem had been defined, and with the purpose of contributing to the evidence available on the topic, this study's main objective was to analyse the extent to which the social dimension was encompassed in the practical management of flood risk in Spain. To this end a documentary content analysis of 14 Spanish flood risk management plans (FRMP) was performed, with the aim of assessing their integration of social actions for risk response and public participation. On the basis of the analysis of these documents, which are the main administrative instrument for flood risk planning in Spain, we attempted to ascertain whether and to what extent Spanish flood risk management is undergoing a shift towards new governance approaches.

\section{METHODOLOGY}

The object of our analysis, as we remarked above, was Spanish FRMPs; thus a sample of 14 approved plans for the different flood zones of the country were used, except that of Catalonia, which lacked homogeneity with the other plans. From each FRMP two documents were chosen for analysis: (a) the "Description of Strategy Programmes" annexe, in which the strategic lines of action aimed at enabling society to respond to the risk are described, and (b) the "Summary of Public Information and Consultation Processes and their Results" annexe. A documentary content analysis was chosen for the purpose. This qualitative analysis used both deductive coding (on the basis of previously defined conceptual categories drawn from the specialised literature) and applied inductive coding (through the creation of codes on the basis of an exhaustive review of the texts in the light of the research objectives and questions). The analysis was performed using the qualitative content analysis software Atlas.ti.

After reviewing the strategic lines described in each document, those with a marked social character were selected. These fell into 5 main types of social strategies: (a) the development of studies for improving knowledge of flood risk management; (b) strategies aimed at setting up or improving institutional planning of responses to flood emergencies through coordinating civil protection plans; (c) improvement of protocols for action and communication of information in cases of flooding; (d) strategies aimed at raising public awareness in preparation for floods, in order to increase flood risk perception and selfprotection among the population and social and economic actors; and (e) civil protection plans: actions for supporting health, financial (including legal) assistance, and the temporary rehousing of affected populations. Each of these strategic lines was specified in turn in "Specific Actions", which were the object of the documentary content analysis.

As we mentioned above, the content analysis was approached in two different ways, corresponding to the two types of documents analysed: first, by analysing the particular actions specified in the different strategic lines; and second, by analysing the quality of the participatory strategies adopted in the process. To analyse the actions from the strategy programme documents, Kuhlicke et al.'s model [29] of social capacity building for natural hazards was used, in Ballester's version [35], adapted to flood risk management in Spain. This model comprises five dimensions: knowledge, motivation, networks, governance and financing. Thus, adopting the social vulnerability approach, we performed an analysis aimed at ascertaining whether these dimensions of capacity-building were reflected in the specific actions programmed in the strategic lines in each FRMP studied. Further, it was chosen to adopt an additional coding model, using the classical agency/social structure pairing. Agency was defined as the tendency of the actions to increase the affected population's individual responsibility and their empowerment to respond to flood risk. As for structure, this was defined as the institutional actions undertaken to create directives and compulsory procedures 
for social actors. This twofold categorisation enabled us to identify the direction of each of the actions making up the strategies.

The documents on public information and consultation were analysed using the model for assessing participation in flood risk management developed by Maskrey et al. [36]. This model assesses the quality of participatory processes in three main dimensions: context, process and outcomes, dividing the latter into substantive and social outcomes. Context indicates the predisposition of the socio-institutional fabric towards participation, embodied in factors such as understanding of the phenomenon of floods, institutional support, previous interactions among stakeholders and the complexity of disputes. Process criteria assess the common characteristics of the participatory processes that impact the efficacy of participation, and are divided into five subcategories: accessibility, deliberation, representation, response and quality. Lastly, social outcomes assesses community capacitybuilding to respond to floods and mitigate vulnerability through participatory processes, analysis of which is subject to the social content of the allegations presented by each participant. It should be noted, however, that the category of substantive outcomes was discarded. This criterion assessed stakeholders' perceptions and attitudes towards expectations, objectives and conflicts once the participatory process was finalised, and was ruled out because the documents studied did not provide this information.

\section{RESULTS AND DISCUSSION}

Our analysis of the results yielded numerous indicators providing answers to our question on the extent to which the social dimension and public participation are included in Spanish FRMPs. The review of actions in the strategy programmes and consultation processes revealed extreme weakness in the integration of the social dimension and merely superficial treatment when it was timidly included in the plans. Firstly, there was a high level of similarity among the social strategies in all the documents from the 14 hydrological regions analysed. This similarity was so strong that on most occasions the actions were described in the exact same words, which would seem to suggest that the social strategies were extracted from a generic model without the necessary adaptation to the particular social context of each case. Despite this, although most of the actions were repeated for all strategies in all the FRMPs, there were a few exceptions in cases that included additional actions formulated exclusively for three regions: the Tagus and West and East Cantabria. Thus the analysis showed very little depth in the social strategies, and an absence of contextualisation of the proposed actions in accordance to the different social situations and specific cultures of each flood zone.

Fig. 1 shows the number of actions in each of the five types of social strategies analysed according to their capacity-building features. The dimension of knowledge (136) was the most frequent, followed by that of networks (108), motivation (42), financing (13) and governance (2). Nevertheless, it should be noted that the sum of elements from all the dimensions of the social capacity-building model (301) did not correspond to the total number of social actions in the strategy documents, since some were classified in more than one capacity-building dimension. The total number of actions was 179; thus, bearing in mind that each FRMP put forward an average of 20 strategic lines and that only five of these were categorized as strategies with social content, the slight proportional weight of the social actions in the whole set of plans becomes evident.

Turning to the orientation of the actions (Fig. 2), it can be observed that the category of structure was noticeably more prominent than that of agency, thereby demonstrating the clear predominance of the socio-structural tendency in the strategic lines, as opposed to actions 


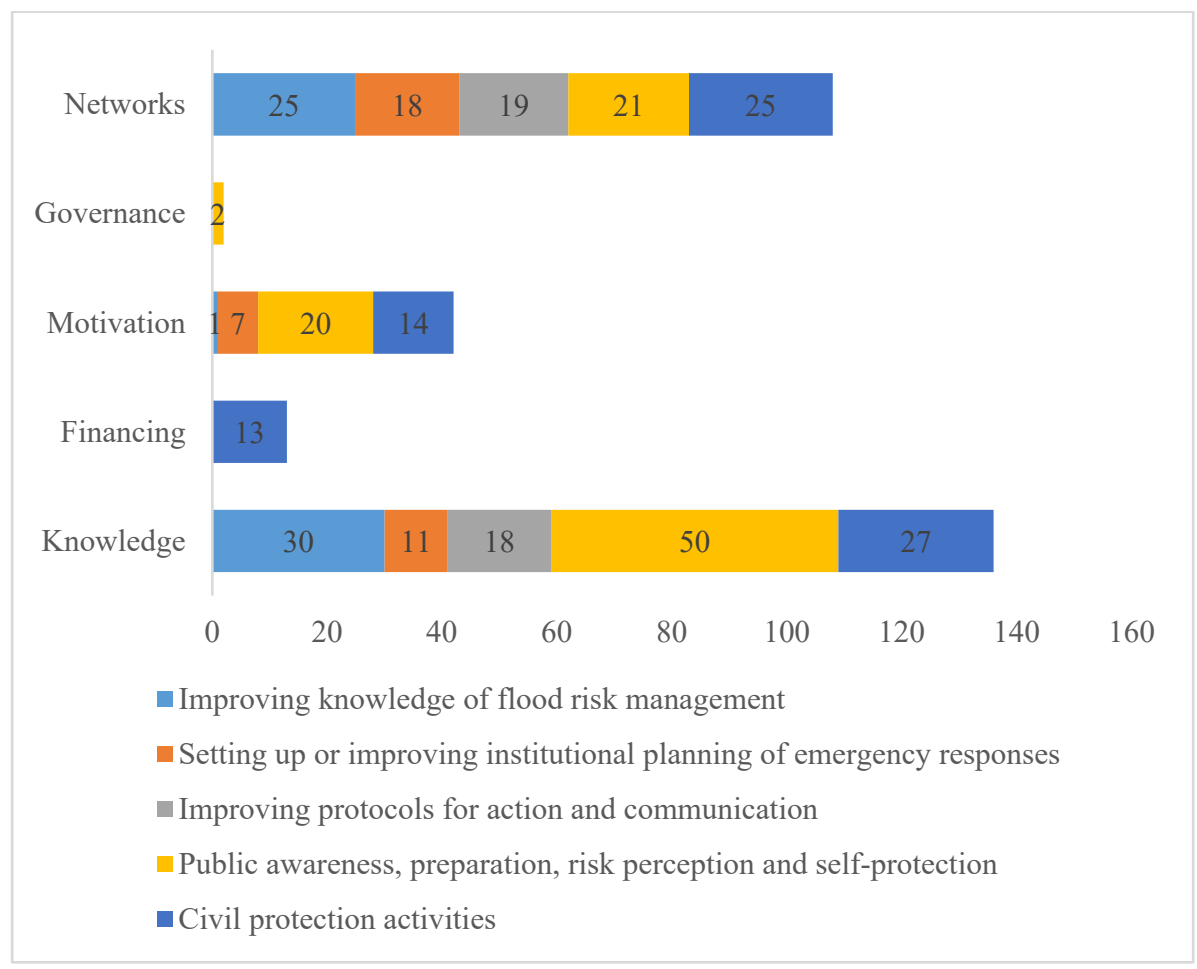

Figure 1: Number of actions according to social strategies and analytical categories. (Source: Own elaboration.)

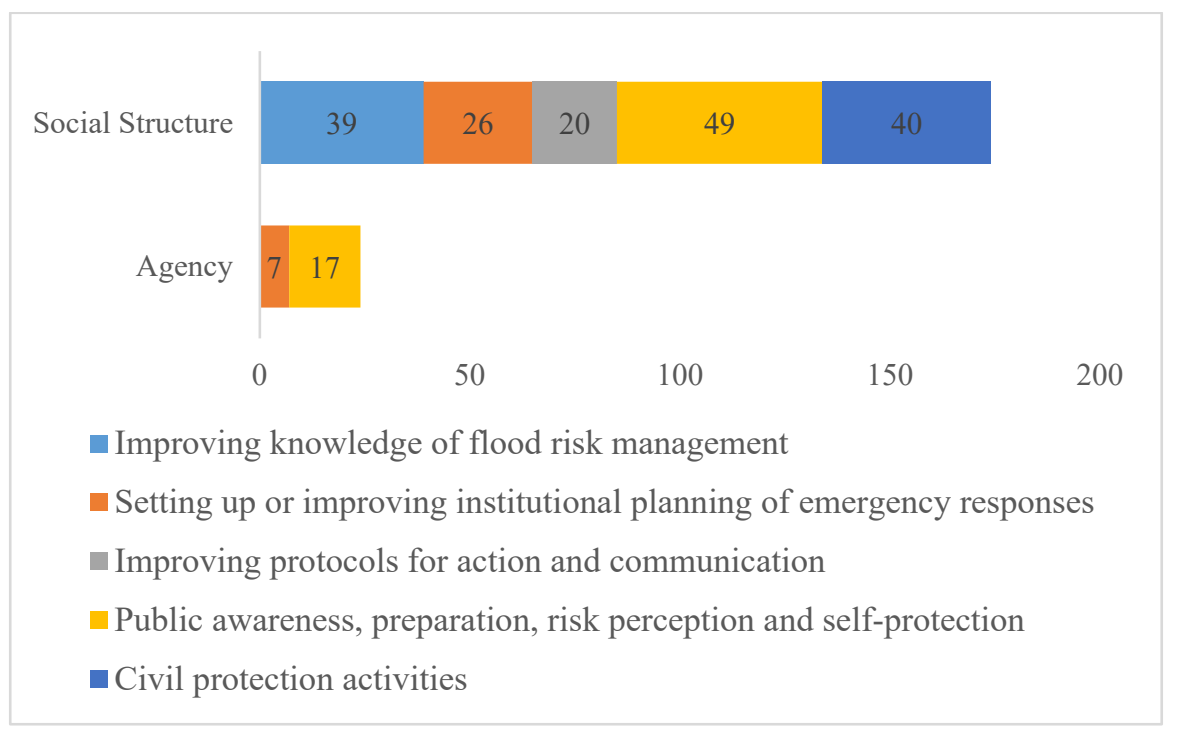

Figure 2: Number of actions according to social strategies and orientation (agency/ structure). (Source: Own elaboration.) 
aimed at individual capacity-building for affected populations (who were thus assigned the role of passive receivers), including even strategies aimed at spreading the knowledge of risk.

Turning our attention to each of the five capacity-building dimensions, we observe that the dimension of knowledge was mainly specified through actions directed towards developing, improving and disseminating knowledge of flood risk and action protocols. These were institutional initiatives focussing on spreading information about self-protection and health guidelines among the population. Nevertheless, there was no observable direct engagement of the institutions themselves in ensuring a solid base of knowledge extending to the whole population, since only references to campaigns and websites appeared, with no actions requiring fluid communication with and direct involvement of the public. In the dimension of networks, the actions were directed towards greater coordination and cooperation among authorities and strengthening the system of actors through information campaigns. This gave increased weight to the socio-structural nature of the strategies, since the dimension revealed greater efforts towards building social capital among the authorities while, in contrast, only marginal attention was given to the networks of actors affected by floods. On the other hand, the actions in the dimension of motivation were closely linked to agency, particularly through the dissemination of guidelines for individual self-protective behaviour. The dimension of financing was, in itself, clear proof of the scarce integration of the social dimension in the strategic lines of the FRMPs: first, only one action of this type emerged, relating to aid and compensation for damages and repeated in exactly the same words in 13 of the 14 FRMPs analysed; and second, its scarce treatment, in terms of both frequency and development, indicated a lack of economic support assigned to carrying out those actions that went beyond merely technical work. The dimension of governance, the last and most underdeveloped category, only appeared in the FRMPs of the areas of West and East Cantabria, which contained actions referring to participatory workshops and questionnaires. In fact, the lack of the governance dimension in the actions also showed Spanish FRMPs to subscribe to a management model directed towards rigid structural measures based on top-down decision-making that did not facilitate collaborative relationships with the affected populations.

Regarding the inclusion of citizen participation strategies in the documents on public information and consultation, our analysis of the context and process categories (composed in turn of the subcategories of accessibility, deliberation, representation, responses and quality) evidenced the lack of detailed information in these categories, also heightened by the homogeneity and rigidity of the documents discussed above. For this reason, it was chosen to make a general descriptive analysis of these categories, aimed at developing an ideal type that would enable us to characterise the nature of public participation in Spanish FRMPs, rather than a systematic coding system and count of codes like that used in analysing the strategies and actions. In the subcategory of representation, on the other hand, it was possible to adopt a strategy of inductive coding, since the documents provided listings of social actors.

The information that the FRMPs provided on the contexts of their participatory processes was limited to mentioning the legislation, specifically Royal Decree 903, 9 July 2010, thereby once again demonstrating a severe lack of adjustment to the particular social and cultural characteristics of each region. Thus the only references to contextual issues were, paradoxically, very similar for all of the flood zones, with no real discussion of the contexts and social needs framing the processes, and with simple justifications indicating only the regulation to be complied with. In the dimension of process, our review revealed the weakness of participation in all five sub-categories. First, it can be concluded that accessibility in the participatory processes of the FRMPs was limited, since there were no 
discernible clear protocols for fostering and publicising participation, and the number of participants in some cases was low. Secondly, the level of deliberation was also low, since this was limited to the exchange of information between the interested party and the government, with no place for dialogue or communication with any other actors. The participatory process, consisting only of the circulation of official documents, allowed for intervention and response solely by the relevant authority, without creating spaces for debate or fluid exchanges of knowledge. In the subcategory of responses, participation in the FRMPs was framed in a rigid procedure restricted to mere application of the existing legislation, without offering the possibility of change through participatory action or adaptation to participants' objectives and timetables. Lastly, since the subcategory of quality referred to professionalism, clarity of objectives and participants' knowledge of what was expected of them, we can speak of a high level of quality, since the formality and the officialadministrative nature of the documents ensured professional participatory processes with clear objectives. In general terms, however, we found participation in the FRMPs to be characterised by rigidity and superficiality, allowing hardly any exchange of knowledge or debate on the key issues. Moreover, the participatory processes were identical for all flood zones, and did not flexibilize or adapt their tools or procedures to the varying social and cultural situations of the different areas of Spain they dealt with.

Turning our attention to representation, as we can see from Fig. 3, the analysis of the public information and consultation documents and their results and the categorization of each of the social representatives participating in the consultation processes revealed a wide variety of actors, with a significantly greater number of companies, regional state bodies and town/city councils than others. Despite this, in our view, participative representation in the FRMPs was relatively low. Bearing in mind the size of each flood zone, many social actors on the local and infralocal scales were left out of account, particularly representatives of citizens' associations, non-state/non-company sectors and individuals with private interests.

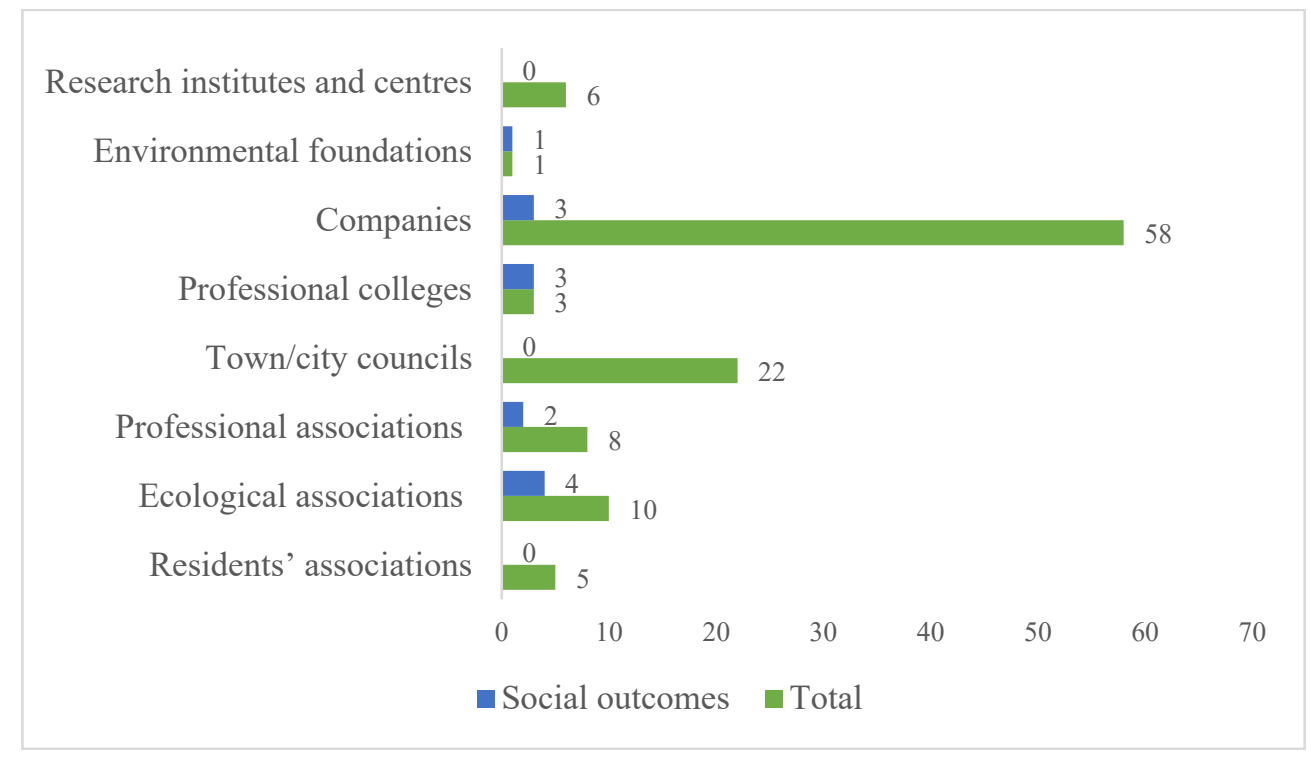

Figure 3: Relative weight of social actors and number of responses to consultation on social outcomes from each actor. (Source: Own elaboration.) 
Thus public bodies on the local, county, regional and national levels were, taken as a whole, the most prominent category. This may demonstrate that consultation processes were not clearly communicated to the public, and that the authorities did not promote greater citizen participation in the design and approval of FRMPs.

Further, it should be noted that in the category of social outcomes, this type of content was scarce compared to technical outcomes or results from structural measures. This deficiency is particularly striking among responses to consultation by state bodies representing the general social interest, such as town/city councils, regional and national governments and even political parties. Most responses to consultation in the area of social outcomes referred to the need to create greater awareness of flood risk and promote selfprotection initiatives, i.e. measures aimed at enhancing the population's individual responsibility. There was virtually no mention of the active involvement of the public in truly participatory processes.

\section{CONCLUSIONS}

In terms of the main objective of this study, it can be concluded that Spanish FRMPs showed significant deficits in integrating the social dimension into the design of action strategies, since the social strategies found were marginal and extremely superficial. Participatory processes also showed severe weaknesses and did not effectively democratise public flood risk management, nor did they sufficiently embrace the social interests of the affected actors in their management strategies. In addition to this, our analysis revealed that attention to social content in the plans was reproduced in a standardised and decontextualised way for the majority of flood zones.

As noted in the preceding sections, this study used a social vulnerability approach to assess the integration of the social dimension into Spanish FRMPs. Our analyses in the areas of strategies and actions and the social results of participatory actions revealed the lack of a firm political commitment to strengthening and improving social capacity-building as a formula for boosting the population's adaptive responses and proactively addressing flood disaster risk. This finding was both clear and explicit, not only in terms of the very small number of social strategies included in the plans, but also in the notable weakness of their content. While these strategic lines seemed to be moving towards some kind of endeavour to overcome the traditional exclusive reliance on structural solutions, at the same time they had strikingly little materialisation in concrete, specific initiatives backed by economic, technical and social incentives. In contrast, the structural measures were sufficiently specific to be put into practice, thus evidencing the persistence and the unchallenged nature of the traditional technocratic paradigm, in which prevention, response and recovery measures are based mainly on technical solutions. Thus we may conclude that Spanish flood disaster risk management is a clear example of the science-policy gap [33], [34]. While scientific research has demonstrated the need to encompass the social dimension and public participation for more effective treatment of natural hazards, public management still reproduces the predominant technocratic paradigm, which has been shown to be insufficient. Thus in our view, the relationships between society and the environment are being recast on the academic and theoretical level, but this has not yet influenced the practical development and implementation of environmental policies. Although some leading international organisations and institutions, such as the European Environmental Agency [37] or the UNDRR [38], have called attention to the need to adopt more proactive and integrated approaches which would allow greater understanding and more effective tackling of socioenvironmental risks, the inclusion of non-structural measures in local management systems and mechanisms is still vague, poorly defined and superficial. In short, addressing the 
question of whether the paradigm is currently shifting or persisting, we would argue that there is clear reproduction and continuance of the predominant technocratic paradigm, with only imprecise and marginal application of specific initiatives and strategies for putting into practice the scientific community's demands for new, more integrated models.

\section{ACKNOWLEDGEMENT}

This study was carried out within the framework of the National Programme for University Teacher Training (FPU) of the Spanish Universities Ministry and funded by a grant awarded to the second author of the paper.

\section{REFERENCES}

[1] Pahl-Wostl, C., Becker, G., Knieper, C. \& Sendzimir, J., How multilevel societal learning processes facilitate transformative change: A comparative case study analysis on flood management. Ecology and Society, 18(4), 2013.

[2] Schoeman, J., Allan, C. \& Finlayson, C.M., A new paradigm for water? A comparative review of integrated, adaptive and ecosystem-based water management in the Anthropocene. International Journal of Water Resources Development, 30(3), pp. 377-390, 2014.

[3] Wolsink, M., River basin approach and integrated water management: Governance pitfalls for the Dutch Space-Water-Adjustment Management Principle. Geoforum, 37(4), pp. 473-487, 2006.

[4] Ayala-Carcedo, F.J., El sofisma de la imprevisibilidad de las inundaciones y la responsabilidad social de los expertos. Un análisis del caso español y sus alternativas. Boletín de la Asociación de Geógrafos Españoles, 33, pp. 79-92, 2002.

[5] Apel, H., Aronica, G.T., Kreibich, H. \& Thieken, A.H., Flood risk analyses: How detailed do we need to be? Natural Hazards, 49(1), pp. 79-98, 2009.

[6] Brown, J.D. \& Damery, S.L., Managing flood risk in the UK: Towards an integration of social and technical perspectives. Transactions of the Institute of British Geographers, 27(4), pp. 412-426, 2002.

[7] Few, R., Flooding, vulnerability and coping strategies: Local responses to a global threat. Progress in Development Studies, 3(1), pp. 43-58, 2003.

[8] Johnson, C.L. \& Priest, S.J., Flood risk management in England: A changing landscape of risk responsibility? International Journal of Water Resources Development, 24(4), pp. 513-525, 2008.

[9] Samuels, P., Klijn, F. \& Dijkman, J., An analysis of the current practice of policies on river flood risk management in different countries. Irrigation and Drainage. The Journal of the International Commission on Irrigation and Drainage, 55(S1), S141S150, 2006.

[10] Jeffers, J.M., Integrating vulnerability analysis and risk assessment in flood loss mitigation: An evaluation of barriers and challenges based on evidence from Ireland. Applied Geography, 37, pp. 44-51, 2013.

[11] Driessen, P.P. et al., Governance strategies for improving flood resilience in the face of climate change. Water, 10(11), p. 1595, 2018.

[12] Shrubsole, D., From structures to sustainability: A history of flood management strategies in Canada. International Journal of Emergency Management, 4(2), pp. 183196, 2007.

[13] Van Buuren, A., Lawrence, J., Potter, K. \& Warner, J.F., Introducing adaptive flood risk management in England, New Zealand, and the Netherlands: The impact of administrative traditions. Review of Policy Research, 35(6), pp. 907-929, 2018. 
[14] Ward, P.J., Pauw, W.P., Van Buuren, M.W. \& Marfai, M.A., Governance of flood risk management in a time of climate change: The cases of Jakarta and Rotterdam. Environmental Politics, 22(3), pp. 518-536, 2013.

[15] Schanze, J. et al., Systematisation, Evaluation and Context Conditions of Structural and Non-structural Measures for Flood Risk Reduction, CRUE Funding Initiative on Flood Risk Management Research: London, 2008.

[16] Kundzewicz, Z.W., Non-structural flood protection and sustainability. Water International, 27(1), pp. 3-13, 2002.

[17] Werritty, A., Sustainable flood management: Oxymoron or new paradigm? Area, 38(1), pp. 16-23, 2006.

[18] Wiering, M. et al., Varieties of flood risk governance in Europe: How do countries respond to driving forces and what explains institutional change? Global Environmental Change, 44, pp. 15-26, 2017.

[19] Fuchs, S., Karagiorgos, K., Kitikidou, K., Maris, F., Paparrizos, S. \& Thaler, T., Flood risk perception and adaptation capacity: A contribution to the socio-hydrology debate. Hydrology and Earth System Sciences, 21(6), pp. 3183-3198, 2017.

[20] Orimoloye, I.R., Belle, J.A. \& Ololade, O.O., Exploring the emerging evolution trends of disaster risk reduction research: A global scenario. International Journal of Environmental Science and Technology, 18, pp. 673-690, 2021.

[21] Birkmann, J. et al., Framing vulnerability, risk and societal responses: The MOVE framework. Natural Hazards, 67(2), pp. 193-211, 2013.

[22] Singh, S.R., Eghdami, M.R. \& Singh, S., The concept of social vulnerability: A review from disasters perspectives. International Journal of Interdisciplinary and Multidisciplinary Studies, 1(6), pp. 71-82, 2014.

[23] Díez-Herrero, A. \& Garrote, J., Flood risk analysis and assessment, applications and uncertainties: A bibliometric review. Water, 12(7), pp. 2050-2074, 2020.

[24] Rufat, S., Tate, E., Burton, C.G. \& Maroof, A.S., Social vulnerability to floods: Review of case studies and implications for measurement. International Journal of Disaster Risk Reduction, 14, pp. 470-486, 2015.

[25] Raška, P., Flood risk perception in Central-Eastern European members states of the EU: A review. Natural Hazards, 79(3), pp. 2163-2179, 2015.

[26] Morrison, A., Westbrook, C.J. \& Noble, B.F., A review of the flood risk management governance and resilience literature. Journal of Flood Risk Management, 11(3), pp. 291-304, 2018.

[27] Renn, O., Risk Governance: Coping with Uncertainty in a Complex World, Earthscan: London, 2008.

[28] Walker, G., Whittle, R., Medd, W. \& Watson, N., Risk governance and natural hazards. CapHaz-Net WP2 Report, Lancaster Environment Centre, University of Lancaster, 2010.

[29] Kuhlicke, C. et al., Perspectives on social capacity building for natural hazards: Outlining an emerging field of research and practice in Europe. Environmental Science and Policy, 14(7), pp. 804-814, 2011.

[30] Raymond, C.M., Fazey, I., Reed, M.S., Stringer, L.C., Robinson, G.M. \& Evely, A.C., Integrating local and scientific knowledge for environmental management. Journal of Environmental Management, 91(8), pp. 1766-1777, 2010.

[31] Hernández-Mora, N. \& Ballester, A., Public participation and the role of social networks in the implementation of the Water Framework Directive in Spain. Ambietalia, 1(Extra 1), pp. 1-21, 2011. 
[32] Nordbeck, R., Löschner, L., Pelaez Jara, M. \& Pregernig, M., Exploring sciencepolicy interactions in a technical policy field: Climate change and flood risk management in Austria, Southern Germany, and Switzerland. Water, 11(8), pp. 16751701, 2019.

[33] Spray, C., Ball, T. \& Rouillard, J., Bridging the water law, policy, science interface: Flood risk management in Scotland. Journal of Water Law, 20(2-3), pp. 165-174, 2009.

[34] Hegger, D., Alexander, M., Raadgever, T., Priest, S. \& Bruzzone, S., Shaping flood risk governance through science-policy interfaces: Insights from England, France and the Netherlands. Environmental Science and Policy, 106, pp. 157-165, 2020.

[35] Ballester, A., Participación pública para una gestión eficaz del riesgo por inundación: construcción de capacidades sociales en la Ribera Alta del Ebro (España). Doctoral thesis, Universitat Autònoma de Barcelona, 2017.

[36] Maskrey, S.A., Priest, S. \& Mount, N.J., Towards evaluation criteria in participatory flood risk management. Journal of Flood Risk Management, 12(2), pp. 1-14, 2019.

[37] European Environmental Agency, Disasters in Europe: More frequent and causing more damage.

https://www.eea.europa.eu/highlights/natural-hazards-and-technological-accidents. Accessed on: 3 Apr. 2021.

[38] UNDRR, Sendai framework for disaster risk reduction 2015-2030. https://www.undrr.org/publication/sendai-framework-disaster-risk-reduction-20152030. Accessed on: 3 Apr. 2021. 